\title{
Experimental Study of Mixed Convection Heat Transfer to Thermally Developing Air Flow in a Horizontal Rectangular Duct
}

\author{
Yasin K. Salman, PhD \\ Energy Engineering Dept. \\ College of Engineering \\ University of Baghdad \\ Baghdad - Iraq
}

\author{
Jalal M. Jalil, PhD \\ Hydro-mechanic Engineering Dept. \\ University of Technology \\ Baghdad - Iraq
}

\author{
Ahmed F. Khudheyer, PhD \\ Mechanical Engineering Dept. \\ College of Engineering \\ Al-Nahreen University \\ Baghdad - Iraq
}

\begin{abstract}
This paper describes the case of combined free and forced convection heat transfer to a thermally developing air flow in a horizontal rectangular duct which has been studied experimentally for laminar internal flow. The heated surfaces were subjected to a constant heat flux while the duct short sides were kept unheated, for three cases lower, upper side heated only and both sides heated with constant heat flux and for fiveduct angles of inclination $0^{\circ}$ (horizontal). In the experimental study, the heat flux applied to the heated surfaces varied from 40 to $400 \mathrm{~W} / \mathrm{m} 2$. This provides a modified Grashof number varied from $2.38 * 106$ to $2.8 * 108$ respectively, while the Reynolds number varied from 800 to 2100. Surface temperature, local heat transfer results reveal a significant effect of buoyancy force created by natural convection on the heat transfer process with the buoyancy makes the thermal boundary layer developed early in comparison with pure forced convection.
\end{abstract}

\section{Keywords}

Mixed Convection Heat Transfer, Thermally Developing flow, constant heat flux, horizontal Rectangular Duct

\section{INTRODUCTION}

Mixed convection is the case of heat transfer that interacting effects between the free and forced convection. It is important to realize that heat transfer in mixed convection can be significantly different from its values in both pure forced and pure free convection. Mixed convection heat transfer inside a vertical and inclined tube is either aiding when the forced convection flow direction is upward or opposing when the forced convection flow direction is downward. Some important applications of mixed convective flow include the design of industrial heat exchangers in chemical and food processing industries where problems may be encountered involving combined convection in horizontal channels, cooling of electrical equipment, the design of certain types of solar energy collectors (flat plate heater) and the estimating of energy time scale required in the case of piping failure in the nuclear power plant. Results of literature survey of mixed convection heat transfer have been conducted to determine the effects of buoyancy on the flow field and the heat transfer. Combined convection heat transfer in fully developed laminar in a constant wall heat flux horizontal circular tube has been reported. Mori et al [1\},\{2\} and \{3] has observed the velocity and temperature profile in a fully developed laminar and turbulent airflow. The results have shown substantial effects of buoyancy on the fully developed velocity and temperature profile. Nusselt numbers in the laminar region were at least twice those calculated by neglecting the effect of density temperature dependence and were found to depend upon the product of Rayleigh and Reynolds numbers (Ra.Re). Bergles and Simonds [4] have investigated the mixed convection effect on water flow in an electrically heated horizontal tube. Visual and quantitative studies have revealed that, in horizontal tubes, the natural convection effect may be important even at relatively low Rayleigh number. Experimental results have shown the circumferential temperature profile on the tube inner wall to have a larger temperature variation created by the buoyancy induced secondary flow. Data correlation in the form of Nusselt number with the dimensionless axial distance $\left(\mathrm{x}^{*}\right)$ for $\mathrm{Ra}$ up to $10^{7}$ have been reported. Morcos and Bergles [5] have carried out tests using a glass tube and stainless steel tube to investigate the effect of temperature dependent fluid properties of distilled water and ethylene glycol flowing in horizontal tubes. The investigation has reported a significant increase in heat transfer when free convection is imposed on forced flow in a horizontal tube. Nusselt number and friction factor were found to depend upon Rayleigh number and the friction factor increases as Rayleigh number increases. The data was correlated for fully developed flow in a horizontal tube giving good agreement. El- Hawary [6] made measurements on water and showed the different flow regions of mixed convection in a constant heat flux horizontal circular tube. Buoyancy appeared to have a significant effect on the laminar flow stability. The different flow regimes were reported. Nusselt number reported showed good agreement with other experimental in the pressure drop along the test section. A wide range of mass flow rates and heat fluxes were covered. Cheng and Hwang [7] have analyzed combined natural and forced convection heat transfer numerically for studies fully developed laminar flow in a horizontal rectangular channel with constant wall heat flux and at two Prandtl numbers. The aspect ratios were from 0.2 to 5.0. A finite difference scheme has been used with a numerical algorithm, which employed the successive over relaxation method. The results revealed an increase in the Nusselt and the friction coefficient as the product of the Reynolds number and Rayleigh number is increased. They also revealed that the increase in Nusselt number was greatest for channels with an aspect ratio near one. The numerical method was used for a range of Re.Ra from 1000 to 4000 and it was found that the method diverges beyond this range. Smyth and Salman [8] studied combined convection heat transfer for a simultaneous developing flow in a rectangular duct. A correlation for duct horizontal duct lower plate heated with a constant heat flux was presented demonstrated the heat transfer enhancement by natural convector at the duct downstream. To study the effects of the inclination duct from horizontal to vertical, situations of heating surface (i.e, upper, lower or both 
sides), and to determine the effects of buoyancy on the flow field and the heat transfer. For the following assumptions: fully developed but developing thermally, steady, three dimensional flow and air flow as a working fluid.

\section{EXPERIMENTAL APPARATUS AND PROCEDURE \\ 2.1 Description of Apparatus}

To investigate experimentally combined convection heat transfer phenomena for thermally developing laminar air flow in a rectangular duct subjected to constant heat flux, the apparatus had been designed and constructed with a general specification of the test rig was determined from the range of working parameters to be covered experimentally and the measuring procedure necessary to obtain the velocity and temperature profiles. In order to scan a full range from a pure free to forced convection heat transfer, the test rig was designed for the following parameters: -

1) Working fluid was air with $\operatorname{Pr}=0.71$.

2) Maximum surface temperature was $\left(120^{\circ} \mathrm{C}\right)$ with a maximum Grashof number, based on the difference between the surface and the air bulk temperature, of $2.8 * 10^{8}$.

3) Mean air velocity at duct inlet up to $0.66 \mathrm{~m} / \mathrm{s}$ with a maximum Reynolds number of 2090.

4) Duct sides to be heated in three ways, upper surface heated only, lower surface heated only or both sides heated with equal heat flux.

5) Horizontal duct.

The apparatus consists essentially of three major parts, the carrier frame (D), rotation plate (E), and an open air circuit consist of inlet duct (C) and test section (B).

The most important of the open air circuit is the test section where most of the measurements were made. The two vertical walls (shorter sides of rectangular duct) as shown in figure 1 The upper and lower walls of test section were designed to be the duct side heated with a constant heat flux so the situation of upper side heated or lower side heated or both side heated can be achieved by powering the side requires. The details of these walls are shown in figures 2 and 3. The heated surface was constructed from three layers glued together to form a composite heater. The composite heater consists of a heating element as nickrom tape $4 \mathrm{~mm}$ wide and $0.01 \mathrm{~mm}$ thick wounded uniformly flat on a $2 \mathrm{~mm}$ mica sheet. The heating element then covered from both sides by $2 \mathrm{~mm}$ mica sheet. The heat element with covers fixed on $2 \mathrm{~mm}$ stainless steel plate to force a composite layer heating element. All thermocouples penetrate the mica layer to be fixed on the stainless steel plate. Thermocouples' locations are mentioned in figures 2 and 3 starting from test section entrance. The heated plates with thermocouples are attached preeminently on a $20 \mathrm{~mm}$ thick $200 \mathrm{~mm}$ wide Teflon plates then a layer of $20 \mathrm{~mm}$ asbestos insulation. The upper and lower heated plate with left and right vertical wall is a assembled together to form a test section. The heat losses through the heat plate lagging were accounted by inserting a thermocouple in the asbestos layer. Then knowing the temperature gradient in the lagging and its thermal conductivity therefore the heat loss by conduction can be evaluated. It was found the losses vary between $(0.02 \%-0.03 \%)$ of the total plate input power.

\subsection{Test Procedure.}

The test procedures involved initially switch on of the main power supply, stabilizer, fan and micro-manometer. After that the main heaters switches were switched on according to side heated. The fan was switched on and its speed adjusted according to the flow meter output desired, usually the low velocity was selected initially. The time to be reading stable was about (30min to $45 \mathrm{~min}$ ). The surface temperature variation along the test section was monitored to verify steady state conditions. After the first run had been recorded, the fan speed increased to the second air velocity reading. The procedure was repeated. After the power (on the heaters) was switched off, the fan was allowed to run for another thirty minutes, which aided the cooling of the test section.

\subsection{Experimental Data analysis}

It is necessary that the term transfer coefficient as used in the present study should be defined clearly, before any calculations are made. The local heat transfer coefficient was calculated from:

$$
\mathbf{h}_{\mathbf{x}}=\frac{\mathbf{q}_{\mathbf{x}}}{\left(\Delta \mathbf{T}_{\mathbf{x}}\right)}
$$

Where $(\Delta \mathrm{T})_{\mathrm{x}}$ was taken as the difference between the local surface temperature $\left(T_{\mathrm{s}}\right)_{\mathrm{x}}$ and the local bulk air temperature $\left(\mathrm{T}_{\mathrm{B}}\right)_{\mathrm{x}}$ at a length (x) from the duct inlet calculated by interpolation between inlet and outlet bulk air temperature. Thus:

$$
\mathbf{h}_{\mathbf{x}}=\frac{\mathbf{q}_{\mathbf{x}}}{\left[\left(\mathbf{T}_{\mathbf{s}}\right)_{\mathbf{x}}-\left(\mathbf{T}_{\mathbf{B}}\right)_{\mathbf{x}}\right]}
$$

The average heat transfer coefficient for any length $\left(h_{L}\right)$ was calculated from:

$$
h_{L}=\frac{1}{L} \int_{x=0}^{x=L} h_{x} d x
$$

The heat transfer from the upper and lower plates was due to the combined effect of radiation and convection, especially with one plate heated. Therefore; the local radiation heat flux was calculated in order to evaluate the net local convection heat flux which is used to calculate the local heat transfer coefficient. The amount of heat transfer with radiation, between two surfaces, was calculated from the following equation:

$$
\left(\mathbf{q}_{\mathrm{rad}}\right)_{\mathrm{X}}=\left(\frac{\sigma\left(\mathrm{T}_{1}^{4}-\mathrm{T}_{2}^{4}\right)}{\left(\frac{1}{\varepsilon_{1}}+\frac{1}{\varepsilon_{2}}-1\right)}\right)
$$

The data analysis was performed. It had the following sequences:

1) Experimental data recorded which includes the temperature variation along sides, the mean inlet velocity, air inlet temperature, air outlet temperature, and duct angle of inclination. The duct side heated and the heater input power.

2) The input temperature in $\left({ }^{\circ} \mathrm{C}\right)$.

3) The surface temperatures were curve fitted by using the least square method.

4) The average wall temperature for different length (L) from the duct inlet was calculated by using the GaussLegendre quadrature.

$$
\left(T_{s}\right)_{L_{L}}=\frac{1}{L} \int_{x=0}^{x=L}\left(T_{s}\right)_{x} \quad d x
$$

5) Total input power was taken from the power supply or by measuring the input main heater current and the voltage by using the volt-multimeter; or only by measuring the current passed through the main heater and applying this relationship:

$$
\mathbf{Q}_{\mathbf{T}}=\mathbf{I} \mathbf{V}
$$

6) The condition heat losses were calculated which varied with air velocity and duct angle of inclination.

7) The total convection and radiation heat transfer could now be calculated from:

$$
\mathbf{Q}_{\text {con }}+\mathbf{Q}_{\text {rad }}=\mathbf{Q}_{\mathrm{I}}-\mathbf{Q}_{\text {cond }}
$$


And the adiabatic convection heat flux from:

$$
\mathbf{q}_{\text {con }+ \text { rad }}=\frac{\left(\mathbf{Q}_{\text {con }}+\mathbf{Q}_{\text {rad }}\right)}{\mathbf{A}}
$$

$\mathrm{Q}_{\text {conv }}$ represents the convectional heat transfer and $\mathrm{A}$ is the plate area

8) The local convection heat flux was obtained from:

$$
\left(\mathbf{q}_{\text {con }}\right)_{\mathbf{x}}=\left(\mathbf{q}_{\text {con }+ \text { rad }}\right)_{\mathbf{x}}+\left(\mathbf{q}_{\text {rad }}\right)_{\mathbf{x}}
$$

9) The local air bulk temperature was obtained from linear interpolation between the inlet and outlet air temperature:

$$
\left(\mathbf{T}_{B}\right)_{\mathbf{x}}=\frac{\left(\mathbf{T}_{\mathbf{0}}-\mathbf{T}_{\mathbf{i}}\right) \cdot \mathbf{x}}{\mathbf{L}}+\mathbf{T}_{\mathbf{i}}
$$

10) The local heat transfer coefficient could now be calculated:

$$
\mathbf{h}_{\mathbf{x}}=\frac{\left(\mathbf{q}_{\text {con }}\right)_{\mathbf{x}}}{\left(\left(\mathbf{T}_{\mathbf{s}}\right)_{\mathbf{x}}-\left(\mathbf{T}_{\mathrm{B}}\right)_{\mathbf{x}}\right)}
$$

And local Nusselt number from

$$
\mathbf{N u}_{\mathbf{D}, \mathbf{x}}=\frac{\mathbf{h}_{\mathbf{x}} \cdot \mathbf{D}_{\mathbf{e}}}{\mathbf{k}_{\mathbf{x}}}
$$

Where $\mathrm{k}_{\mathrm{x}}$ is thermal conductivity evaluated at $\left(\mathrm{T}_{\mathrm{av}}\right)$

In order to study the effect of force convection on forced convection, a local Grashof number was defined:

$$
\mathbf{G} \mathbf{r}_{\mathbf{D}, \mathbf{x}}=\frac{\boldsymbol{\beta} \mathbf{g}\left(\left(\mathbf{T}_{\mathbf{S}}\right)_{\mathbf{x}}-\left(\mathbf{T}_{\mathbf{B}}\right)_{\mathbf{X}}\right) \mathbf{D}_{\mathbf{e}}^{3}}{\boldsymbol{v}_{\mathbf{x}}^{2}}
$$

Grashof numbers was based on the plate heat flux can also be used and are defined as:

$$
\mathbf{G r}_{\mathbf{D}, \mathbf{q}_{\mathrm{x}}}=\frac{\beta \mathrm{gD}_{\mathrm{e}}^{4} \mathbf{q}_{\mathrm{x}}}{\mathbf{k}_{\mathrm{x}} \mathbf{v}_{\mathrm{x}}^{2}}
$$

The above dimensionless groups were calculated by the same sequence as for the average heat transfer coefficient. All the property values using in calculating these parameters were contained from least square polynomial fits are used (in terms of temperature) with the properties evaluated at the mean fluid temperature at each axial location. An algorithm was written FORTRAN computer language in order manipulates and analyzes the experimental data. The computer program capable to evaluate all air properties depending on polynomial type equations calculated in a very high accuracy.

\subsection{Experimental Uncertainty}

Uncertainty or deviations may be due to several reasons when it comes to experimental measurements.. In the present work, the uncertainties in heat transfer coefficient (Nusselt number), Reynolds number and Rayleigh number were estimated based on the Kline and McClintock differential approximation method reported by Holman [9]. For a typical experiment, the total uncertainty in measuring the surface to bulk air temperature, voltage of the heater, current of the heater, Diameter, Average lagging surface temperature and the flowmeter were $0.15 \%, 0.05 \%, 0.0004 \%, 0.0003 \%, 0.08 \%$, and $0.04 \%$, respectively. These were combined to give a maximum error of $2.5 \%$ in heat transfer coefficient (Nusselt number), maximum error of $2.3 \%$ in Rayleigh number, and maximum error of $0.09 \%$ in Reynold number.

\section{RESULT AND DISCUSSION}

Experimental results and discussion for a thermally laminar air flow in a rectangular duct with upper and lower plates subjected to constant heat flux is presented.

\subsection{Velocity and Temperature profiles.}

To investigate the effect of the duct orientation on mixed convection in rectangular duct with an aspect ratio $\left(A_{p}=5: 1\right)$,experiments were carried out by using five-hole pressure and temperature probes to demonstrate the velocity and temperature profiles, for the air flow through the duct respectively. Probes traverse vertically between two plates that for $\mathrm{y}=0$ means the probe at lower plate and for $\mathrm{y}=40 \mathrm{~mm}$ means that the probe at upper plate. The Reynolds number and Grashof number based on the equivalent duct diameter and the surface heat flux were kept almost constant and equal to 2000 and $2.2 * 10^{7}$ respectively. In all the above tests, the measurements have been made in three positions across the duct, i.e., duct center, 4-cm off-center and 8-cm off-center.

Three tests have been carried out for the horizontal duct, and the results for upper side heated only, lower side heated only and for both sides heated, is shown in figures 4,5 and 6 , respectively.

In figure 4 , for upper plate heated only reveals the beginning of flow restriction at the duct center on the profile for duct center goes to nearly zero value near the upper heated side. The profiles 4 and $8-\mathrm{cm}$ off center show a reduction in the velocity near to upper plate and for these profiles the maximum velocity bias toward lower plate. For the temperature profile, the three profiles considered showing no difference in the duct lateral width sharp increase in the thermal boundary layer at the approximately upper half of the duct. In figure 5, it shows that the velocity and temperature profiles for the case of lower side heated only. Comparison, with figure 4 , the center line profile shifted toward the upper plate while the 4 and $8 \mathrm{~cm}$ off center gradually moves toward the lower plate because of the high temperature at the lower surface. This means that the thickness of the boundary layer will be larger than that at the upper surface. Figure 6 show the temperature and velocity profiles for the condition where both sides are heated with the same value of heat flux. It shows the onset of movement of the profile toward the lower plate. The temperature profile shows approximate symmetry around the middle of the duct height with a little shift toward the lower plate. In figure 6 , the duct center velocity profile is biased toward the lower plate, the $4-\mathrm{cm}$ off-center profile moves again toward the lower plate. The temperature profiles, in figure 6 , confirm the existence of longitudinal vortices by showing transverse temperature variations suggested by the temperature increase from the duct center to the $4 \mathrm{~cm}$ off-center position and then a decrease to the $8 \mathrm{~cm}$ off-center. This temperature variation means the temperature is high in the region where the buoyancy created flow is moving upward and low where it is moving downward.

\subsection{Heat transfer measurements.}

The results of the heat transfer to the air flow through the rectangular horizontal duct can be presented for the following cases.

\subsubsection{Upper side heated only}

For the upper plate heated only, heat flux varying from $40 \mathrm{~W} / \mathrm{m}^{2}$ to $398 \mathrm{~W} / \mathrm{m}^{2}$ and the range of Reynolds number from 855 to 1022, the results are shown in figures 7 and 8. Figure 7 shows the variation of the measured surface temperature along the heated surface. The curves show similar behavior for all heat fluxes with surface temperature increasing along the duct which 
the same in the theoretical results. The variation of the heat transfer coefficient along the duct is shown in figure 8. It shows a small improvement in heat transfer coefficient as the heat flux increases, especially at low heat fluxes. At the moderate and high heat fluxes, the results show small effect of heat flux change on the heat transfer process.

This behavior can be attributed to the existence of a strong natural convection boundary layer dominating regions near to the upper plate due to the change in ambient temperature from inlet to exit will effect on the density between the layers of air in the vertical direction. Hence, the local heat transfer coefficient $h_{x}$ is shown in figure 8 , decreases with duct length asymptotically. The higher heat flux runs show higher $h_{x}$ at the duct inlet, but they decrease with length of the duct because of increasing the difference between the surface and the bulk temperatures respectively along the duct. Figure 9 explains the variation of $\mathrm{Nu}_{\mathrm{L}}$ with dimensionless axial distance $\mathrm{x}^{*}$, which shows an effect of heat flux with all the curves merging together with $20 \%$.

\subsubsection{Lower plate heated only}

Test runs covered five heat fluxes varying from $68 \mathrm{~W} / \mathrm{m}^{2}$ to 395 $\mathrm{W} / \mathrm{m}^{2}$ with four Reynolds number for each heat flux varying from 1095 to 1158. Figure 10 shows the variation of measured surface temperature along the duct and demonstrates completely different trends to that obtained with upper plate heated only case. The surface temperature increases at the duct inlet and then decreases in the rest of the duct. This behavior is shown clearly in figure 11 , which gives the variation of local heat transfer coefficient $h_{x}$ along the duct. The value of $h_{x}$ decreases rapidly at the duct inlet and then it increases for the rest of the duct. The improvement of the heat transfer coefficient can be attributed to the onset of the longitudinal vortices which enhance the heat transfer process. Figure 12 shows the variation of $\mathrm{Nu}_{\mathrm{L}}$ with dimensionless axial distance $x^{*}$.

\subsubsection{Both sides heated}

Test runs were carried out for this case to cover five heat fluxes, varying from $43 \mathrm{~W} / \mathrm{m}^{2}$ to $250 \mathrm{~W} / \mathrm{m}^{2}$ with four Reynolds number per set varying from 720 to 749 . These runs data and results, for upper plate, lower plate and average of both plates, are shown in figures 13 to 15 . Surface temperature variation along the duct shown in figure 13 illustrates that temperature difference between the upper and lower plates for the same Reynolds number increases as the heat flux is increased due to increasing buoyancy effects with the divergence point moving towards the duct inlet as the heat flux increases. These temperature distributions show similar trends to that occurring with either upper plate or lower plate heated only cases, but in the lower plate heated case the reduction in surface temperature is higher as the result of the existence of a strong boundary layer adjacent to the upper plate. Figure 14 shows the variation of the local heat transfer coefficient $\left(\mathrm{h}_{\mathrm{x}}\right)$ along the duct for the upper plate, lower plate and the average for both sides. It reveals that for the intermediate and high heat flux runs, the local heat transfer coefficients for the upper plate are not affected by the increasing of the heat flux whereas the lower plate shows a large improvement in $h_{x}$ as heat flux increases. Figure 15 shows the variation of $\mathrm{Nu}_{\mathrm{L}}$ with dimensionless axial distance $\mathrm{x}^{*}$ and behavior in the same way for the previous.

\subsubsection{Reynolds number effects}

Reynolds number effects on the heat transfer process in a horizontal duct are given in figures 16 to 18 . Figure 16 depicts the variation of the duct average Nusselt number $\mathrm{Nu}_{\mathrm{L}}$ with
Reynolds number for the upper plate heated case and for different average Grashof number $\left(\mathrm{Gr}_{\mathrm{Dq}}\right)$. It shows a small improvement in average Nusselt number $\mathrm{Nu}_{\mathrm{L}}$ as the Reynolds number increases for each Grashof number and shows no effect of the increasing Grashof number on the Nusselt number, especially at low range of Reynolds number. In fact, the highest Grashof number shows a reduction in its Nusselt number values in comparison with the moderate Grashof number tests. This behavior can be attributed to the existence of the recirculation flow penetrating the upper plate boundary layer which increases the surface temperature and reduces the heat transfer process especially at low Reynolds number. Figure 17 shows the variation of average Nusselt number $\mathrm{Nu}_{\mathrm{L}}$ with Reynolds number for the lower plate heated case. It shows a high improvement in the $\mathrm{Nu}_{\mathrm{L}}$ value in comparison with the upper side heated case given in figure 17 for the same Grashof number $\mathrm{Gr}_{\mathrm{Dq}}$. The trends of the variation depict an increase in $\mathrm{Nu}_{\mathrm{L}}$ in the $\mathrm{Re}_{\mathrm{D}}$ range between 400-900 and at a rate increasing with increase of Grashof number beyond this $\mathrm{Re}_{\mathrm{D}}$ range the trends shows a reduction in $\mathrm{Nu}_{\mathrm{L}}$ for low and moderate Grashof numbers and remains approximately constant for the high Grashof number test for the rest of the Reynolds number range. This behavior indicates that the secondary flow vortices effect is high in the Reynolds number range from 400-900, but this effect will diminish for low and moderate Grashof number test runs and will increase further beyond this range of Grashof number test runs for the both sides heated case. Figure 18 shows the variation of the average Nusselt number for both sides heated with Reynolds number. The results indicate that as the heat flux varies the upper plate $\mathrm{Nu}_{\mathrm{L}}$ is approximately constant at very low values in comparison with lower side heated only result. This is due to the strong upper plate boundary which tends to protect the upper plate from the secondary flow vortices. The secondary flow vortices appear to have a large effect on the lower plate and the core of the duct only. Therefore, the variation of $\mathrm{Nu}_{\mathrm{L}}$ for both sides' shows the same trends as that for the lower side heated only, but with lower values especially in the Reynolds number range 400-900.

\subsection{Horizontal Duct Lower plate heated only Correlations}

It has been known, for some time, that the natural convection effects are not always negligible when considering forced convection. From the experimental study, and for the range of heat flux and Reynolds numbers tested, it was found that, for air, free convection effects can seldom be neglected when considering the lower plate of a horizontal parallel plate channel with uniform heat flux.

\subsubsection{Development of a Semi - Empirical Formula for the Lower Plate}

The empirical correlation of fully developed flow and developing thermally is taken from the Shah and London [10] with an error of $4.4 \%$ in its results comparison with the other results. This empirical correlation is:

$$
\mathrm{Nu}_{\mathbf{x}}=1.953\left(\mathrm{X}^{*}\right)^{-1 / 3}
$$

The development of an empirical correlation for the combined heat transfer is an important task into consideration both the natural and forced convection effect on a flow flowing in a horizontal parallel plate channel. There are many different possible forms for this correlation. The form which appears to be the most appropriate is:

$$
\mathbf{N u}_{\mathbf{m}}^{\mathrm{n}}=\mathbf{N u _ { \mathrm { F } } ^ { \mathrm { n } }}+\mathbf{N} \mathbf{u}_{\mathbf{N}}^{\mathrm{n}}
$$


The natural convection component is represented by the correlation for turbulent free convection from a heated horizontal plate facing upward which is suggested by Holman, can be expressed as:

$$
\mathrm{Nu}_{\mathrm{D}, \mathrm{N}}=0.15\left(\mathrm{Gr}_{\mathrm{D}} \cdot \mathrm{Pr}\right)^{1 / 3}
$$

The relation between the two Grashof numbers is:

$$
\mathbf{G r}_{\mathbf{D}}=\frac{\mathbf{G r}_{\mathbf{D}, \mathbf{q}}}{\mathbf{N u}_{\mathbf{D}}}
$$

Using this relationship, the Grashof number based on temperature difference in equation (17) can be replaced by $\mathrm{Gr}_{\mathrm{D}}$ based on the lower plate heat flux rearranging equation (17), gives:

$$
\mathrm{Nu}_{\mathrm{D}, \mathrm{N}}=0.622\left(\mathrm{Gr}_{\mathrm{D}_{\mathrm{q}}} \cdot \mathrm{Pr}\right)^{1 / 4}
$$

Substituting equations (15) and (19) into equation (16), with $\mathrm{n}=2$, gives:

$$
\left.\frac{N u_{M}}{N u_{F}}=\sqrt[2]{\left[1+0.102\left(\frac{x}{D}\right)^{0.667} \frac{\sqrt[2]{\operatorname{Gr}_{D_{q}}}}{\operatorname{Re}_{D}^{0.667} \cdot \operatorname{Pr}^{0.1667}}\right]}\right]
$$

A comparison of the present data and the correlation in depicted in figure 19, shows that the correlation matches the data well, certainly within the experimental uncertainty of the data.

\section{CONCLUSIONS}

Experimental and theoretical studies have been performed to determine the effects of the secondary flow created by natural convection on a fully-developed air flow in a rectangular duct. The duct boundary conditions have been combined into horizontal duct. The horizontal duct results reveal the following conclusions:-

1. The flow adjacent to upper plate both for the upper plate heated only and both sides heated conditions, is mainly a laminar, forced convection boundary layer but at a high heat flux and low Reynolds number, the probability of having recirculation is high. The flow adjacent to the lower plate, for the lower plate heated only and both sides heated, is greatly affected by secondary flow which creates longitudinal vortices.

2. The surface temperature of the upper plate is approximately proportional to the plate heat flux while for the lower plate, it is proportional to heat flux only near the test duct inlet. This behavior makes the temperature difference between the upper and lower plates, in the both sides heated case, increase as the heat flux increases.

3. The upper plate $\mathrm{Nu}_{\mathrm{L}}$ is approximately independent of plate heat flux. Therefore; the comparison of the upper plate correlation with pure forced convection, for a fully-developed flow between constant heat flux parallel plates, is in good agreement. The lower $\mathrm{Nu}_{\mathrm{L}}$ is affected greatly by the plate heat flux. These effects enhance the heat transfer and reduce the duct inlet effect.

4. Ge A semi-empirical equation for the laminar mixed convection for the lower plate has been developed which shows that the effect of natural convection must be considered when $\left|\left(\frac{x}{D}\right)^{0.667} \frac{G r_{D q}^{0.5}}{R e_{D}^{0.667} \operatorname{Pr}^{0.1667}}\right| \leq 30$.
5. The correlation predicts an improvement in heat transfer, for the highest applied heat flux, of as much as $98 \%$ compared with that for the pure forced convection results.

\section{ACKNOWLEDGMENT}

The author gratefully acknowledges the financial support for this study received from the Energy Department, College of Engineering, and University of Baghdad

\section{REFERENCES}

[1] Mori Y.,Futagami k., Nakamura M. and Tokuda S. , (1966). "Forced convection heat transfer in uniformly heated horizontal tubes, $\left(1^{\text {st }}\right.$ report - Experimental study)", Int. J. of Heat and Mass Transfer, vol. 9, pp. 453-463.

[2] Mori Y. and Futagami k. (1978). "Forced convection heat transfer in uniformly heated horizontal tubes", $2^{\text {nd }}$ report, theoretical study Int. J. of Heat \&Mass Transfer, vol.10, pp 1801-1813,

[3] Mori et. al (1979) "An analysis of laminar combined forced and free convection heat transfer in the horizontal tubes", Int. J. of Heat and Mass transfer, vol. 12, pp. 12951309 ,.

[4] Bergles A. B. and Simonde R. R. (1971). "Combined forced and free convection for laminar flow in horizontal tubes with uniform heat flux", Int. J. of Heat and Mass Transfer, vol. 14, pp. 1989-2000,

[5] Morcos S. M. and Bergles A. E. (1975) "Experimental investigation of combined forced and free laminar convection in horizontal tubes", Trans. ASME, J. of Heat Transfer, pp. 212-219, May.

[6] El-Hawary M. A. (1980) "Effect of combined free and forced on the stability of horizontal tubes", Trans. ASME, J. of Heat Transfer, vol. 102, pp.273-278, May.

[7] Cheng K. C. and Hwang G. J. (1969). "Numerical solution for combined free and forced laminar convection in horizontal rectangular channels", Trans. ASME, J. of Heat Transfer, Feb pp.53-66,

[8] Smyth R., and Salman, Y. K. (1991) "Combined free and forced convection heat transfer in a rectangular duct', Int. Comm. Heat Mass Transfer" Vol.18, PP. 669-680,

[9] Holman J. P. (Jack Philip), (2011). "Experimental methods for engineers", 8th ed. McGraw-Hill Series in Mechanical Engineering

[10] Shah R. K. and London A. L. (1978). 'Laminar Flow Forced Convection In A Duct', Advanced in Heat Transfer, Supplement 1, Academic Press,

\section{APPENDIX}

\section{NOMENCLATURE}

\begin{tabular}{|c|lc|}
\hline A & Duct cross - sectional area, & $\mathrm{m}^{2}$ \\
\hline $\mathrm{A}_{\mathrm{P}}$ & Duct aspect ratio & \\
\hline $\mathrm{C}_{\mathrm{p}}$ & Specific heat at constant pressure & $\mathrm{J} / \mathrm{kg} .{ }^{\circ} \mathrm{K}$. \\
\hline $\mathrm{D}_{\mathrm{e}}$ & Equivalent duct diameter, & $\mathrm{m}$ \\
\hline $\mathrm{g}$ & Acceleration due to gravity & $\mathrm{m} / \mathrm{s}^{2}$ \\
\hline $\mathrm{h}$ & Convective coefficient of heat transfer & $\mathrm{W} / \mathrm{m}^{2} \cdot{ }^{\circ} \mathrm{C}$ \\
\hline $\mathrm{K}$ & Thermal conductivity, & $\mathrm{W} / \mathrm{m}^{\circ}{ }^{\circ} \mathrm{C}$. \\
\hline $\mathrm{L}$ & Duct length & $\mathrm{m}$ \\
\hline $\mathrm{q}$ & Total surface heat flux & $\mathrm{W} / \mathrm{m}^{2}$ \\
\hline $\mathrm{q}_{\mathrm{c}}$ & Surface Convective heat flux & $\mathrm{W} / \mathrm{m}^{2}$ \\
\hline $\mathrm{q}_{\mathrm{r}}$ & Surface radiative heat flux & $\mathrm{W} / \mathrm{m}^{2}$ \\
\hline $\mathrm{Q}_{\mathrm{T}}$ & Total surface input heat & $\mathrm{W}$ \\
\hline
\end{tabular}




\begin{tabular}{|c|lc|}
\hline $\mathrm{Q}_{\text {con }}$ & Net surface convective heat & $\mathrm{W}$ \\
\hline $\mathrm{Q}_{\text {rad }}$ & Net surface radiative heat & $\mathrm{W}$ \\
\hline $\mathrm{Q}_{\text {cond }}$ & Net conduction heat loss & $\mathrm{W}$ \\
\hline $\mathrm{T}$ & Temperature & ${ }^{\circ} \mathrm{C}$ \\
\hline $\mathrm{u}$ & Velocity component in the x-direction & $\mathrm{m} / \mathrm{s}$ \\
\hline $\mathrm{v}$ & Velocity component in the y-direction & $\mathrm{m} / \mathrm{s}$ \\
\hline $\mathrm{w}$ & Velocity component in the z-direction & $\mathrm{m} / \mathrm{s}$ \\
\hline $\mathrm{x}$ & Distance in the axial coordinate & $\mathrm{m}$ \\
\hline $\mathrm{y}$ & Cross-stream vertical coordinate & $\mathrm{m}$ \\
\hline $\mathrm{z}$ & Cross-stream span wise coordinate & $\mathrm{m}$ \\
\hline
\end{tabular}

Subscript

\begin{tabular}{|c|l|}
\hline b & Both plates \\
\hline B & Bulk or mixing cub \\
\hline f & film \\
\hline F & Pure forced convection \\
\hline i & Duct Inlet conditions \\
\hline l & Lower plate \\
\hline L, av & average \\
\hline max & maximum \\
\hline M & Mixed convection \\
\hline N & Pure natural convection \\
\hline O & Duct exit air \\
\hline X & Local \\
\hline S & surface \\
\hline u & Upper plate \\
\hline 1 & Emitted surface \\
\hline 2 & Absorbed surface \\
\hline
\end{tabular}

\section{Greek symbol}

\begin{tabular}{|c|c|c|}
\hline$\varepsilon$ & Emissivity of the surface & \\
\hline$\beta$ & Thermal expansion coefficient & $1 /{ }^{\circ} \mathrm{K}$ \\
\hline$\rho$ & Density, & $\mathrm{kg} / \mathrm{m}^{3}$ \\
\hline$\mu$ & Dynamic viscosity, & $\mathrm{kg} / \mathrm{m} \cdot \mathrm{s}$ \\
\hline$v$ & Kinematics viscosity, & $\mathrm{m}^{2} / \mathrm{s}$ \\
\hline$\Delta \mathrm{T}$ & Temperature difference & \\
\hline$\sigma$ & Stefan - Boltzman constant $=5.67$ & $\mathrm{~W} / \mathrm{m}^{2} \cdot \mathrm{k}$ \\
\hline
\end{tabular}

\section{Dimensionless Groups}

\begin{tabular}{|c|c|}
\hline $\mathrm{Gr}_{\mathrm{L}}$ & Average Grashof number, $\beta \mathrm{gL}^{3}(\Delta \mathrm{T})_{\mathrm{L}} / v^{2}$ \\
\hline $\mathrm{Gr}_{\mathrm{x}}$ & Local Grashof number, $\beta \mathrm{g} \mathrm{x}^{3}(\Delta \mathrm{T})_{\mathrm{x}} / v^{2}$ \\
\hline $\mathrm{Gr}_{\mathrm{D}}$ & Grashof number based on $\mathrm{D}_{\mathrm{e}}, \beta \mathrm{gD}^{3}(\Delta \mathrm{T})_{\mathrm{x}} / \mathrm{v}^{2}$ \\
\hline $\mathrm{Gr}_{\mathrm{Dq}}$ & Grashof No.based on heat flux, $\left(\beta \mathrm{gD}_{\mathrm{e}}{ }^{4} \mathrm{q}\right) /\left(\mathrm{k} \cdot \mathrm{v}^{2}\right)$ \\
\hline $\mathrm{Nu}_{\mathrm{L}}$ & Average Nusselt number, $\left(\mathrm{h}_{\mathrm{L}} . \mathrm{L} / \mathrm{k}\right)$ \\
\hline $\mathrm{Nu}_{\mathrm{x}}$ & Local Nusselt number, $\left(\mathrm{h}_{\mathrm{x}} \cdot \mathrm{x} / \mathrm{k}\right)$ \\
\hline $\mathrm{Nu}_{\mathrm{D}}$ & Nusselt number based on $\mathrm{D},\left(\mathrm{h}_{\mathrm{L}} \cdot \mathrm{D} / \mathrm{k}\right)$ \\
\hline $\operatorname{Pr}$ & Prandtl number, $\left(\mu \mathrm{C}_{\mathrm{p}} / \mathrm{k}\right)$ \\
\hline $\mathrm{Ra}_{\mathrm{L}}$ & Average Rayleigh number, $\left(\mathrm{Gr}_{\mathrm{L}} \cdot \operatorname{Pr}\right)$ \\
\hline $\mathrm{Ra}_{\mathrm{x}}$ & Local Rayleigh number, $\left(\mathrm{Gr}_{\mathrm{x}} \cdot \mathrm{Pr}\right)$ \\
\hline $\mathrm{Ra}_{\mathrm{D}}$ & Rayleigh number based on $\mathrm{D},\left(\mathrm{Gr}_{\mathrm{D}} \cdot \mathrm{Pr}\right)$ \\
\hline $\mathrm{Ra}_{\mathrm{Dq}}$ & Rayleigh number based on heat flux, $\mathrm{Gr}_{\mathrm{Dq}} \cdot \mathrm{Pr}$ \\
\hline $\mathrm{Re}_{\mathrm{D}}$ & Local Reynolds number based on $\mathrm{D},\left(\mathrm{u}_{\mathrm{i}} . \mathrm{D} / \mathrm{v}\right)$ \\
\hline
\end{tabular}

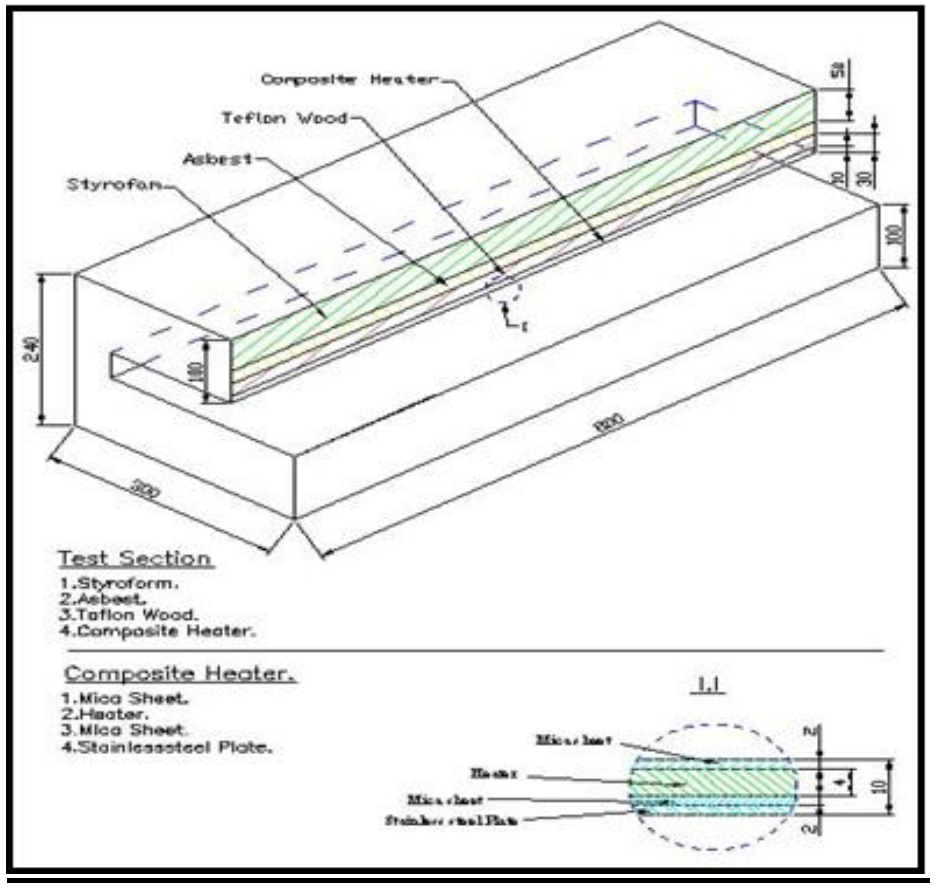

Fig 1 Test section duct composition

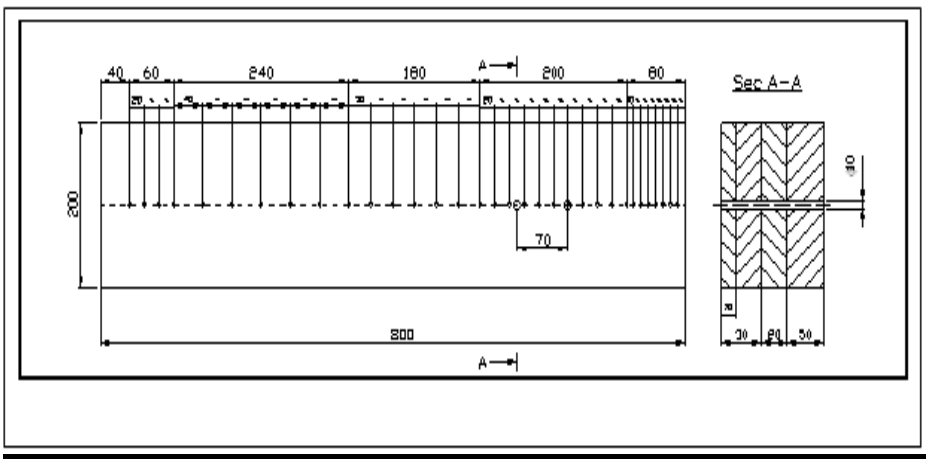

Fig 2 Locations of thermocouples on upper plate heated

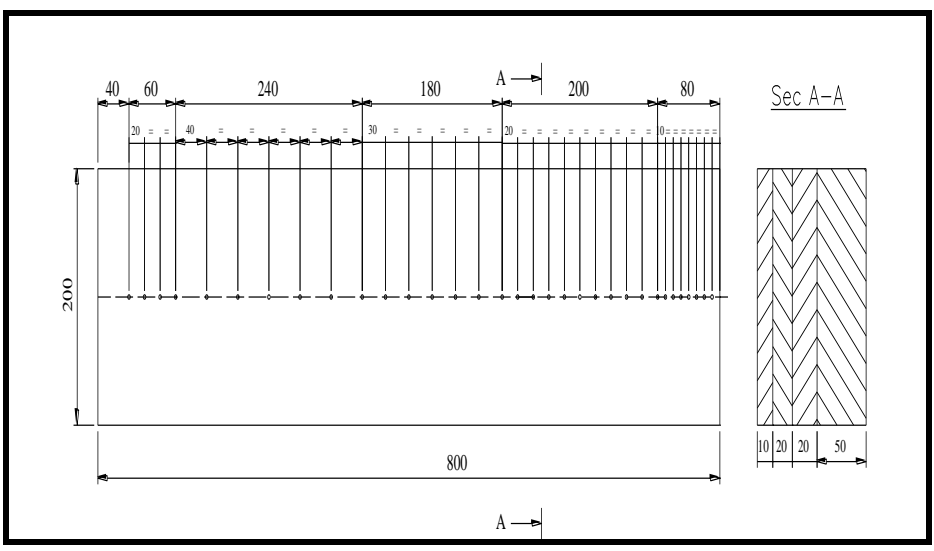

Fig 3 Locations of thermocouples on lower plate heated 


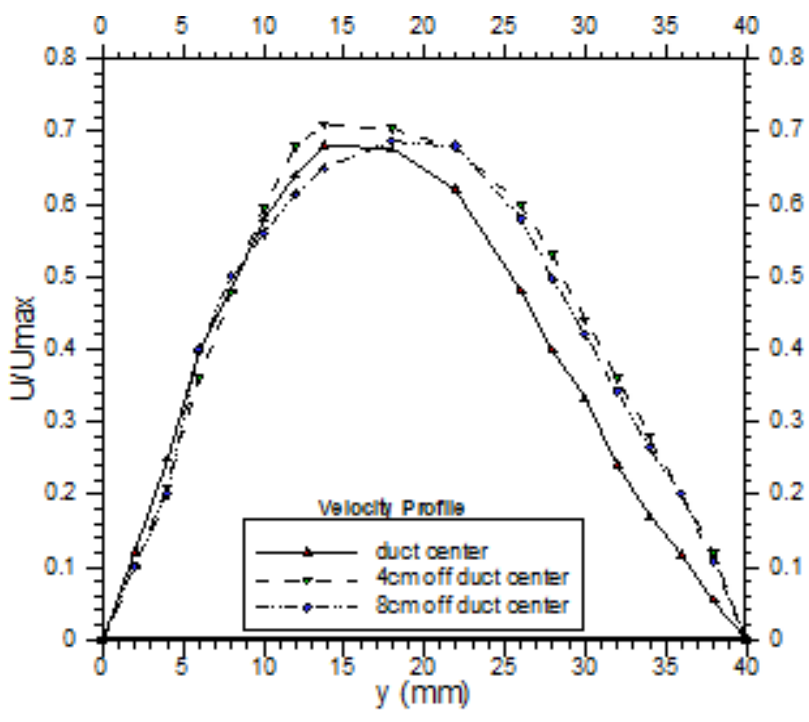

Fig 4-a Velocity profile, upper plate heated, $\operatorname{Re}_{\mathrm{De}}=\mathbf{9 3 0}$

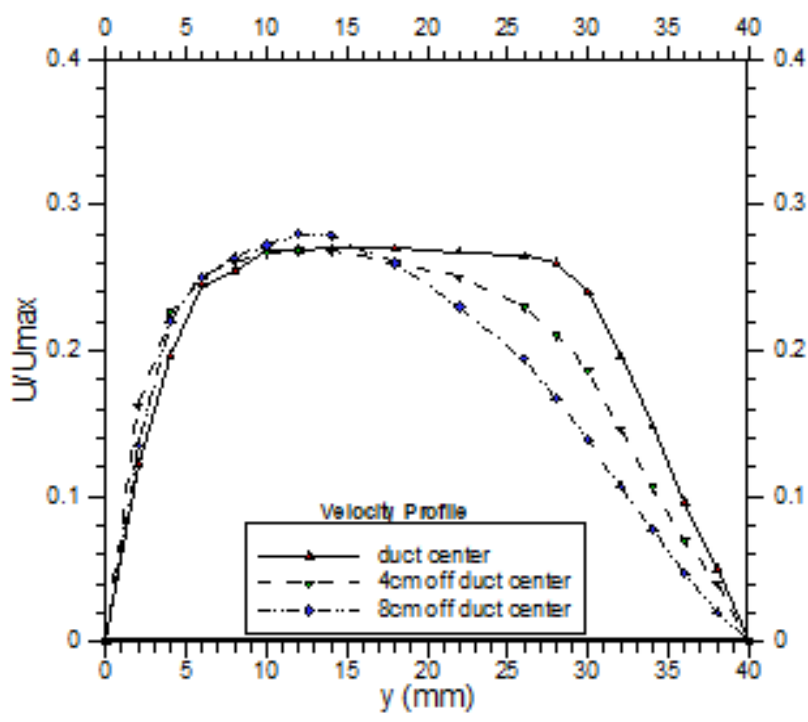

Fig 5-a Velocity profile, lower plate heated, $R_{D_{D e}}=930$

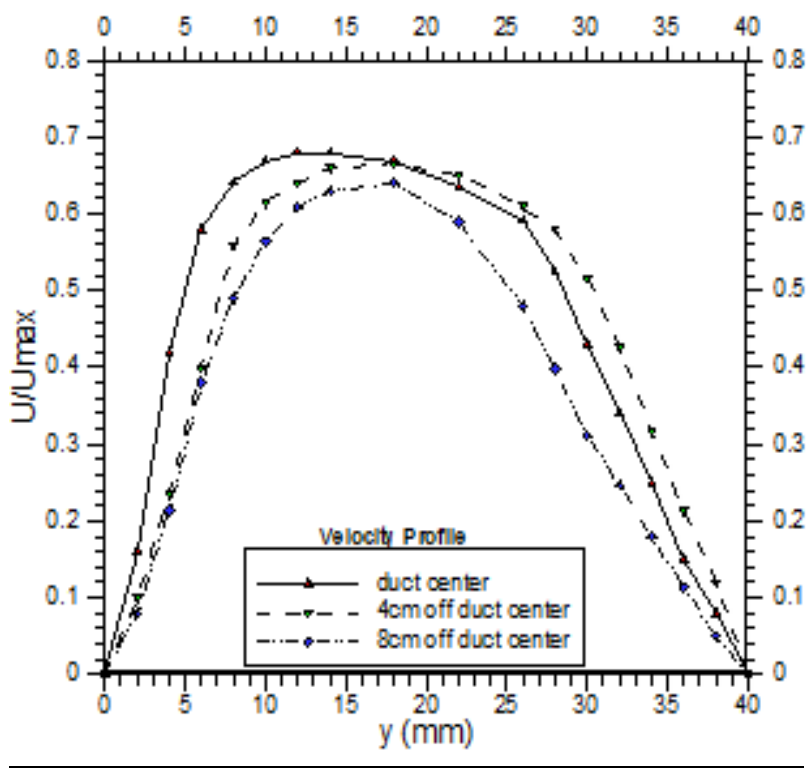

Fig 6-a Velocity profile, both plates heated, $\mathrm{Re}_{\mathrm{De}}=2054$

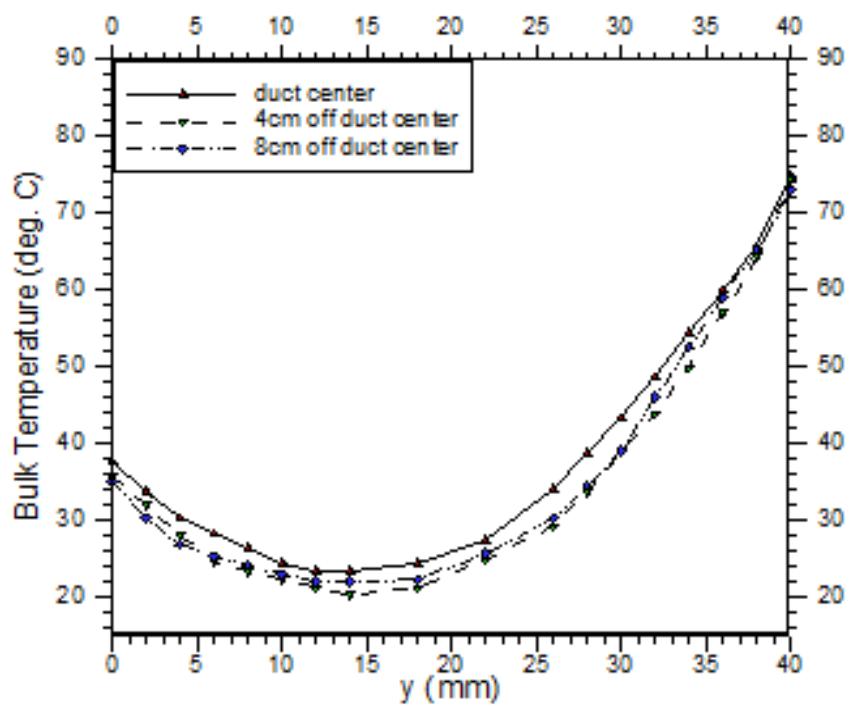

Fig 4-b Temperature profile, upper plate heated, $\operatorname{Re}_{\mathrm{De}}=\mathbf{9 3 0}$

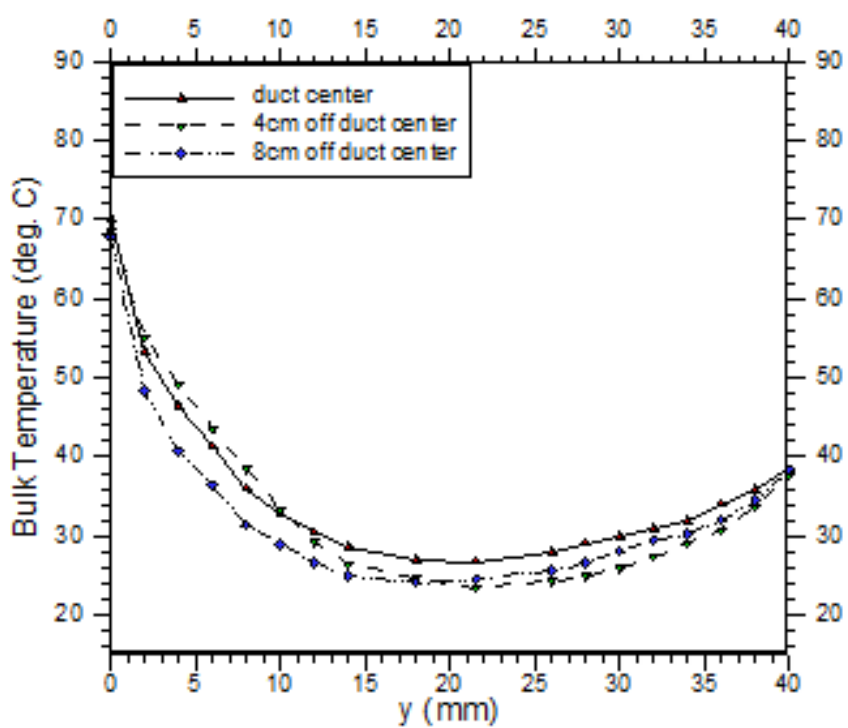

Fig 5-b Temperature profile, lower plate heated, $R_{\mathrm{De}}=930$

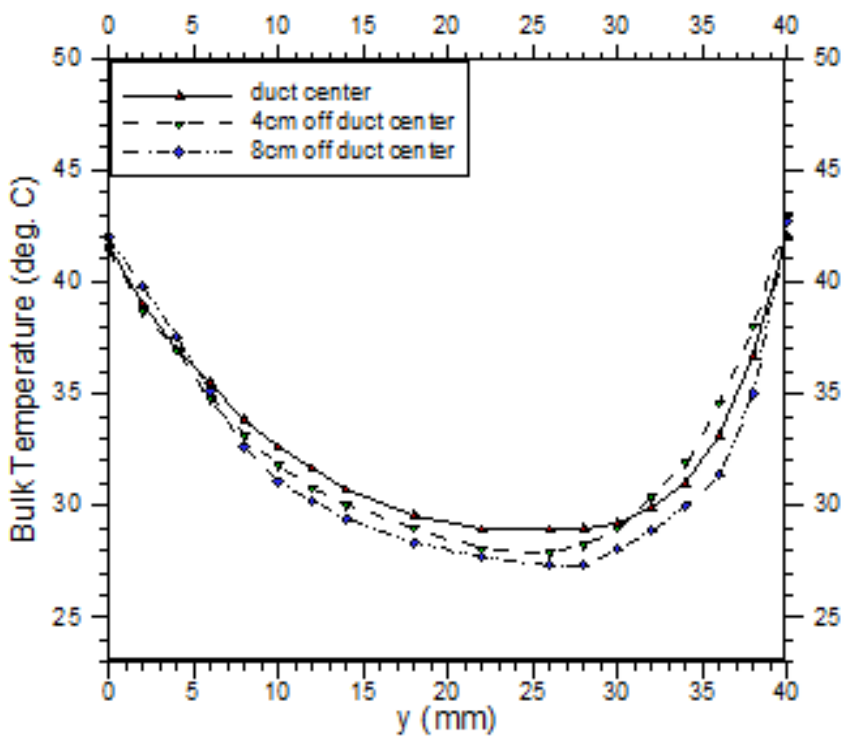

Fig 6-b Temperature profile, both plates heated, $\mathrm{Re}_{\mathrm{De}}=$ 2054 


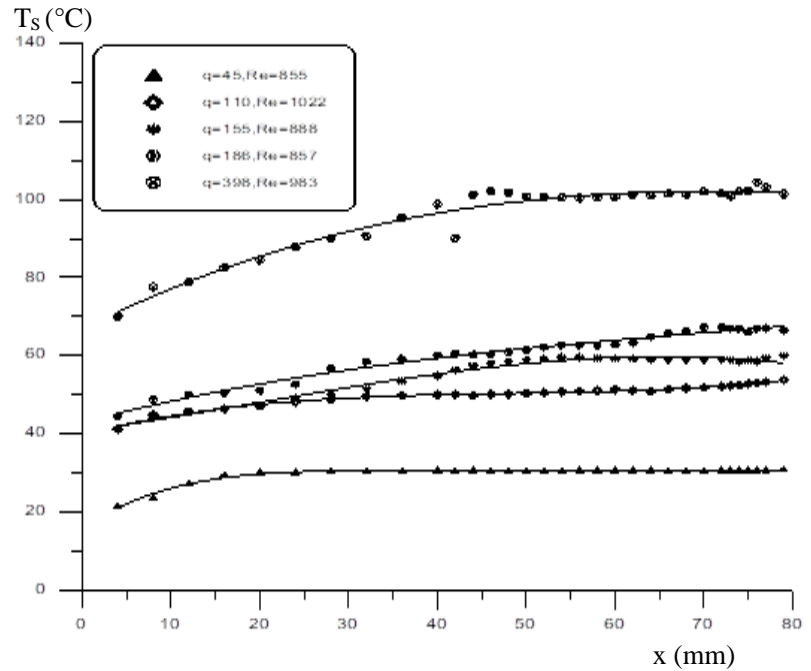

Fig 7 Axial variation of heated surface temperature, horizontal duct, upper plate heated only

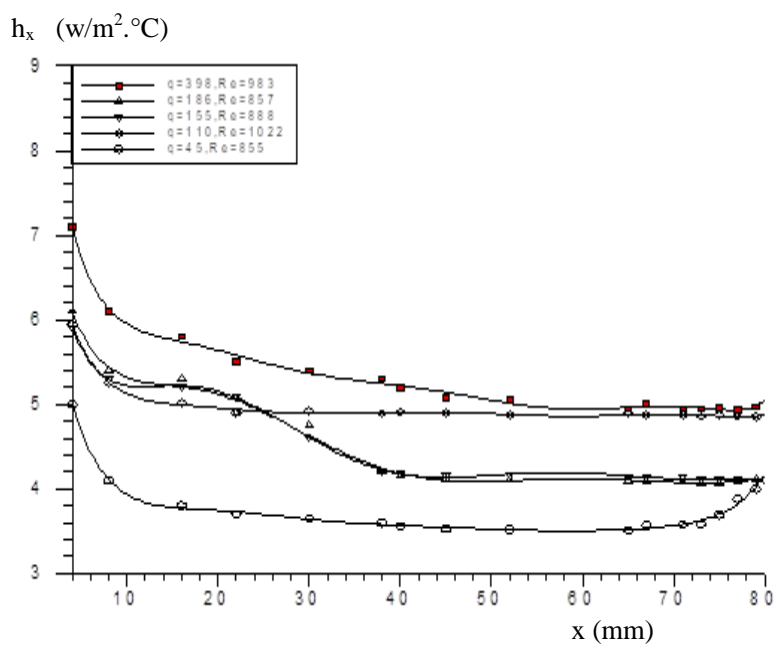

Fig 8 Axial variation of local heat transfer coefficient horizontal duct, upper side heated only

Average Nusselt number $\mathrm{Nu}_{\mathrm{L}}$

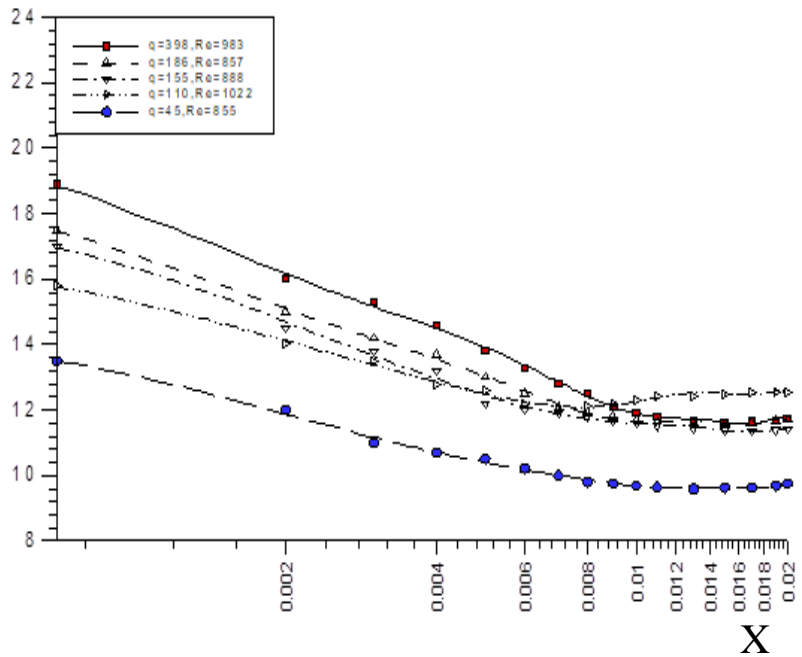

Fig 9 Axial variation of average Nusselt number with $X^{*}$, horizontal duct, upper plate heated only.

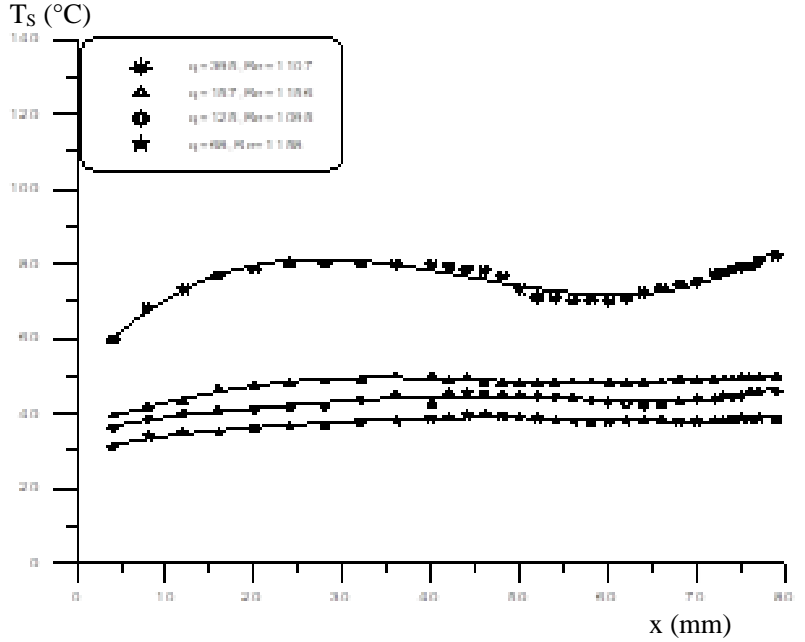

Fig 10 Axial variation of heated surface temperature, horizontal duct, lower plate heated only

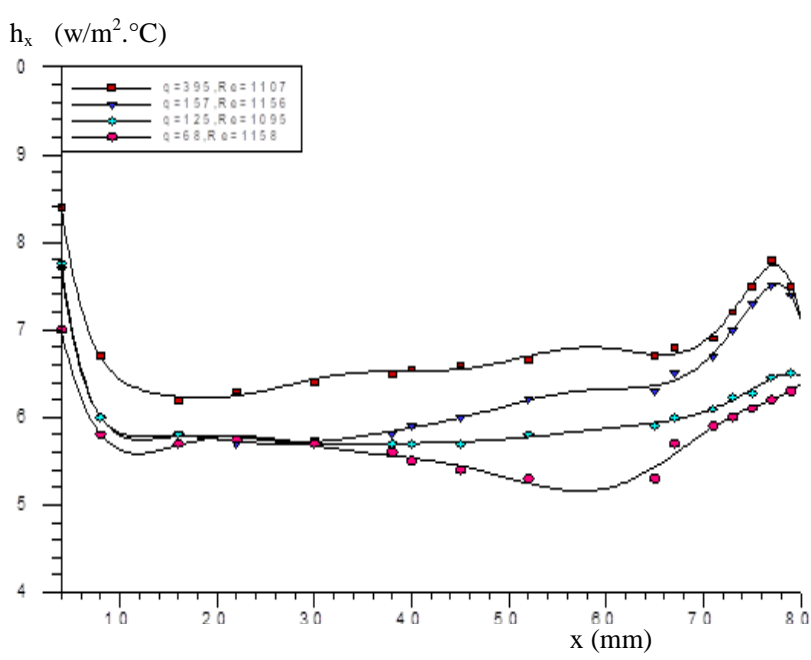

Fig 11 Axial variation of local heat transfer coefficient horizontal duct, lower plate heated only

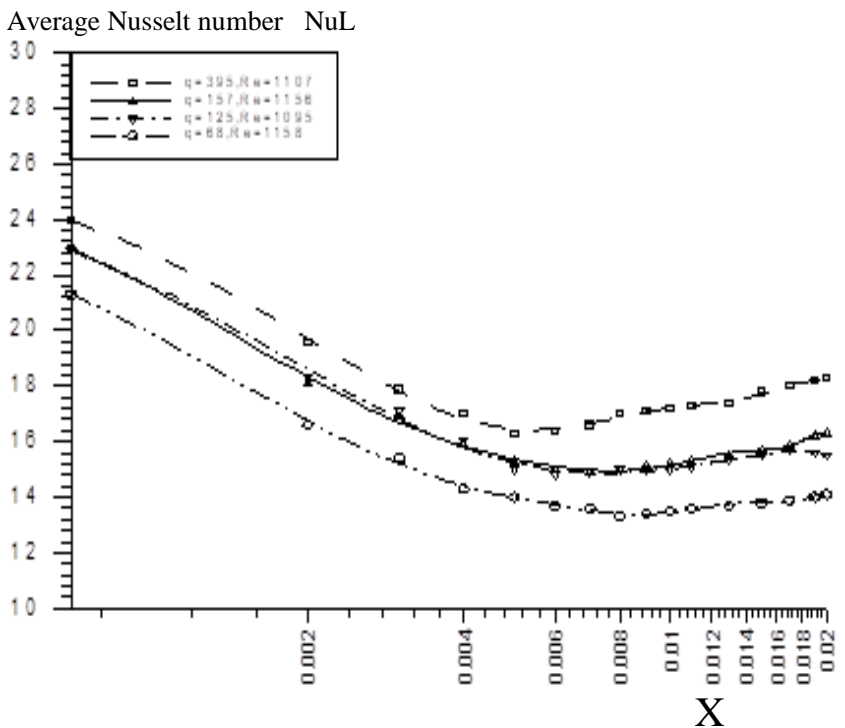

Fig 12 Axial variation of average Nusselt number with $X^{*}$, horizontal duct, lower plate heated only 


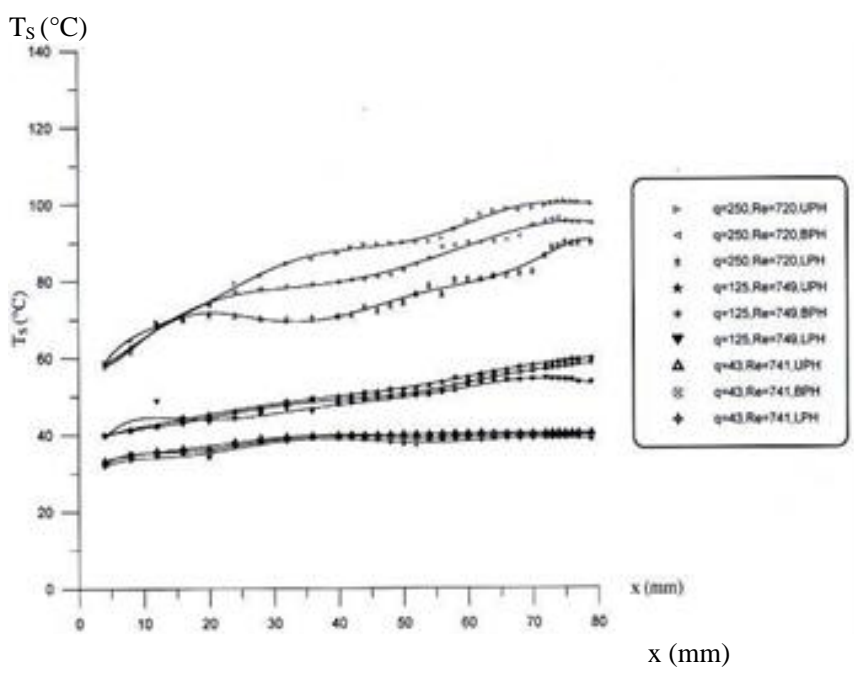

Fig 13 Axial variation of heated surface temperature, horizontal duct, both plates heated

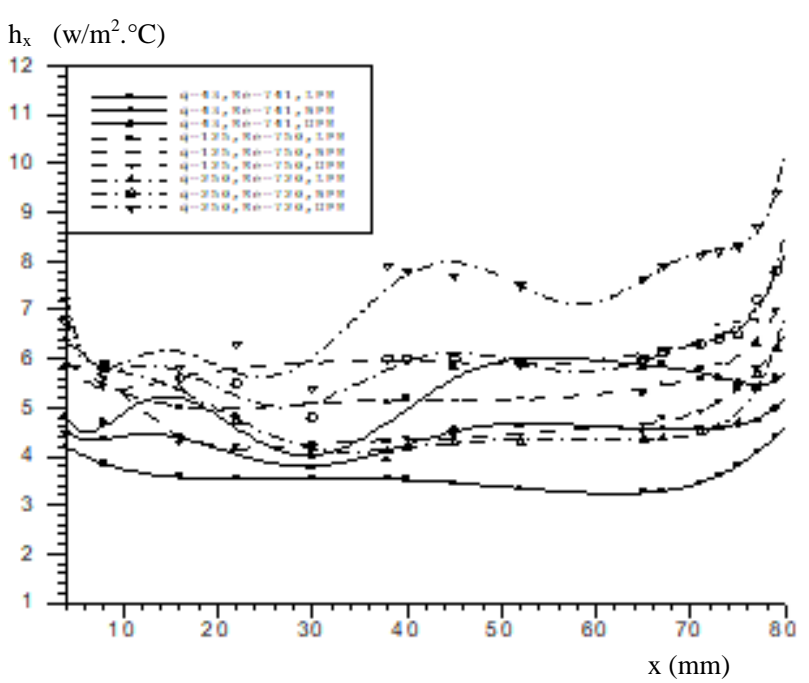

Fig 14 Axial variation of local heat transfer coefficient horizontal duct, both plates heated

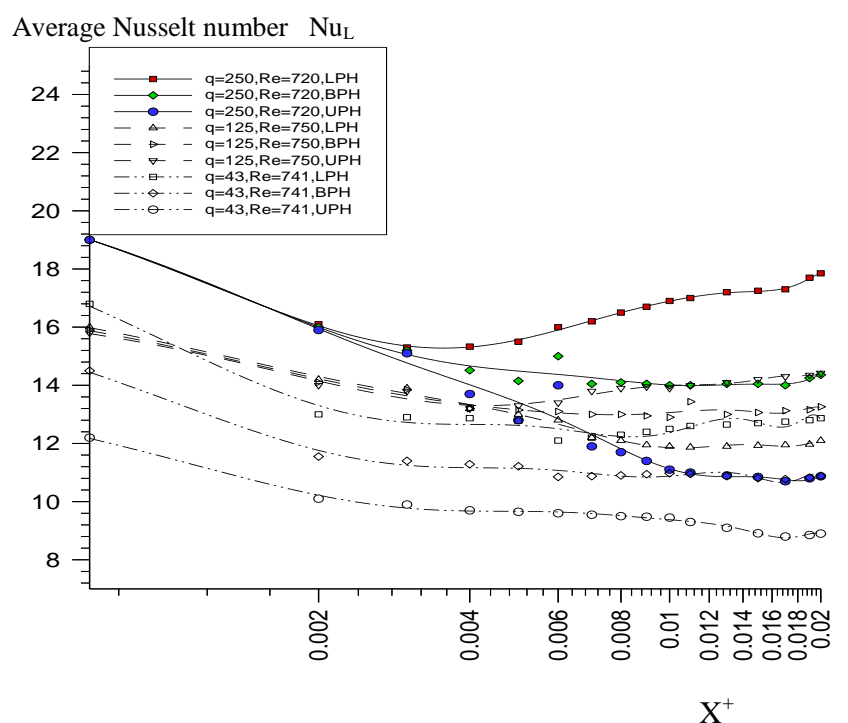

Fig 15 Axial variation of average Nusselt number with $X^{*}$, horizontal duct, both plates heated

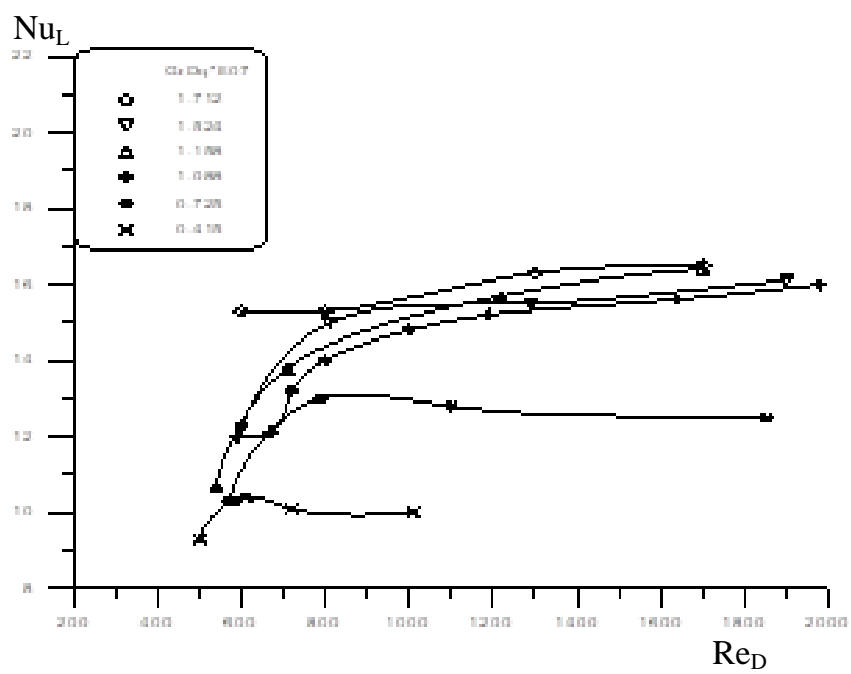

Fig 16 Variation of $\mathrm{Nu}_{\mathrm{L}}$ with $\mathrm{Re}_{\mathrm{D}}$ horizontal duct. Upper plate heated

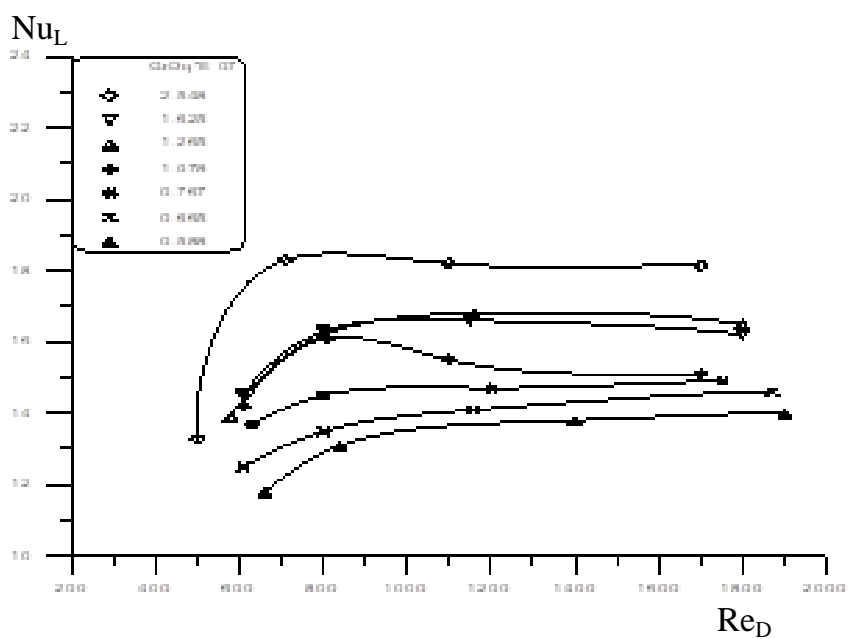

Fig 17 Variation of $\mathrm{Nu}_{\mathrm{L}}$ with $\mathrm{Re}_{\mathrm{D}}$ horizontal duct. Lower plate heated

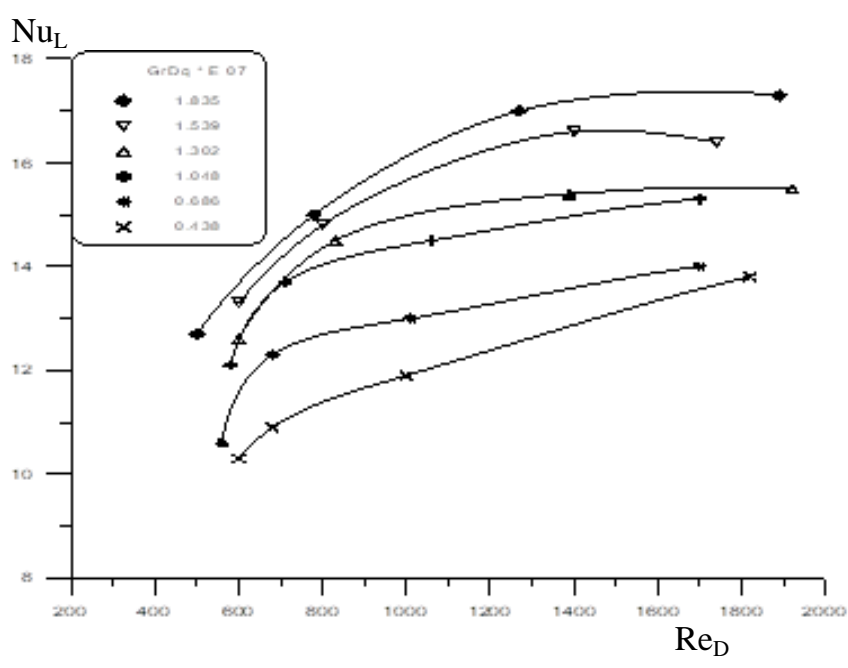

Fig 18 Variation of $\mathrm{Nu}_{\mathrm{L}}$ with $\mathrm{Re}_{\mathrm{D}}$ horizontal duct. Lower plate heated 


$$
\frac{N u_{m_{L}}}{N u_{F}}
$$

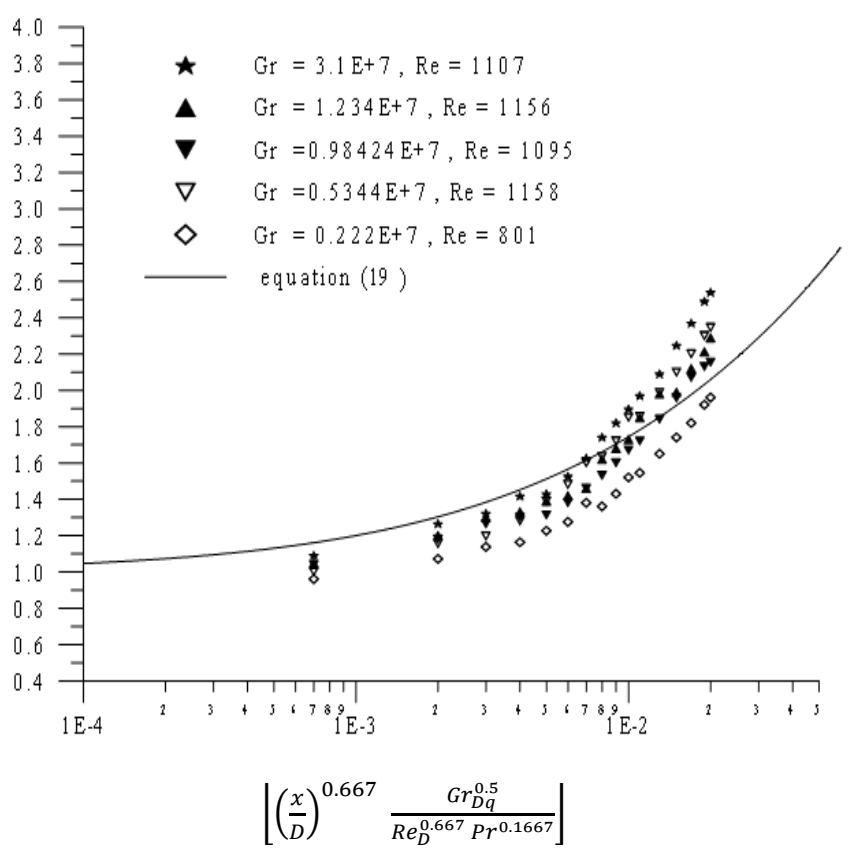

Fig. 19 Horizontal duct lower plate results correlation 